\title{
PRESPECTIVAS DA EDUCAÇÃO PROFISSIONAL DIANTE DO CONTEXTO ATUAL DO MUNDO DO TRABALHO
}

\author{
Josimar de Aparecido Vieira, Cristiane Longaray Radke \\ Instituto Federal de Educação, Ciência e Tecnologia do Rio Grande do Sul - Campus Sertão \\ DOI: 10.15628/rbept.2019.6051
}

Artigo submetido em jun/2017 e aceito em jun/2018

\begin{abstract}
RESUMO
Este trabalho é parte integrante de uma pesquisa desenvolvida no Curso de Pós-Graduação em Teorias e Metodologias da Educação intitulada "Desafios da educação profissional e tecnológica diante das expectativas dos estudantes" do IFRS - Campus Sertão. Teve como objetivo compreender as finalidades da educação profissional diante do contexto atual do mundo do trabalho. Constituído numa abordagem qualitativa, foi produzido por meio de pesquisa bibliográfica. Encontra-se organizado da seguinte forma: na primeira parte, denominada "Globalização e o mundo do trabalho" são examinados aspectos relacionados com o mundo do trabalho na atualidade tendo a dimensão da globalização como conjuntura de análise. Na segunda parte, denominada "Educação profissional e suas finalidades", são apresentadas finalidades da educação profissional, vista como possibilidade concreta de ingresso e manutenção das pessoas no mundo do trabalho. Para a produção dessas partes foram analisados trabalhos que foram desenvolvidos e publicados na literatura acadêmica, abarcando posições e tendências de autores que vem pesquisando sobre a temática nos últimos anos. Constatou-se, entre outros aspectos, que a educação profissional precisa ser tratada como processo educativo ampliado e relacionado com as exigências do mundo do trabalho. Os resultados deste estudo apontam para a compreensão de que a educação profissional precisa rever suas finalidades no sentido de incorporar conhecimentos nos currículos e na prática educativa voltada para um mundo de trabalho que mantém sintonia com demandas provenientes da sociedade.
\end{abstract}

Palavras-Chave: Contexto atual. Mundo do Trabalho. Educação Profissional.

\section{PROSPECTS OF PROFESSIONAL EDUCATION BEFORE THE CURRENT CONTEXT OF THE WORLD OF WORK}

\begin{abstract}
This work is an integral part of a research developed in the Postgraduate Course in Theories and Methodologies of Education entitled "Challenges of professional and technological education in the face of student expectations" of the IFRS - Campus Sertão. It aimed to understand the aims of professional education in the current context of the world of work. In the first part, entitled "Globalization and the world of work" are examined issues related to the world of work today, having the dimension of globalization as a conjuncture of analysis. In the second part, called "Professional education and its purposes", are presented purposes of professional education, seen as a concrete possibility of entry and maintenance of people in the world of work. For this it's necessary that it be treated as an educational process enlarged and related to the demands of the world of work. In the production of these parts are involved works that have been developed and published in the academic literature, including positions and tendencies of authors who have been researching this subject in recent years. The results of this study point to the understanding that professional education needs to revise its purposes in order to incorporate knowledge in the curricula and in the educational practice aimed at a world of work that keeps in tune with demands coming from society.
\end{abstract}

Keywords: Current context. World of work. Professional education. 


\section{INTRODUÇÃO}

O processo educativo se mostra como uma necessidade nos dias atuais. Dentre as reivindicações apontadas para este processo destaca-se a preparação de cidadãos e profissionais para um mundo do trabalho em permanente mudança. Parte-se do princípio que o processo ensinoaprendizagem pode permitir experiências educacionais sem precedentes, fazendo uso de ferramentas indisponíveis anteriormente (vias digitais, internet, robótica, etc.), sendo que tais circunstâncias podem contribuir para uma formação profissional direcionada para novas oportunidades do mundo do trabalho.

Profissionais cujas formações permitem o desenvolvimento apenas de trabalhos manuais e de baixa complexidade possivelmente estarão excluídos do mundo de trabalho e com dificuldades em obter sucesso e satisfação profissional. De encontro a isso, acentua-se a necessidade da formação profissional que traz junto um conceito de socialização e autonomia. As ferramentas, as técnicas, os conteúdos e os procedimentos estão em constante mutação e as pessoas precisam de incessante atualização. Diante deste avanço tecnológico, constatam-se dois pontos de vista: de um lado encontram-se os entusiastas da educação de qualidade e universalizada, que veem a facilidade dos jovens em incorporar tantas informações e do outro, visto como lado oposto tem-se os pensadores que questionam esta educação e seu real efeito diante de um mundo do trabalho tão dinâmico.

Perante dessas considerações, a qualificação profissional se faz necessária. Torna-se necessário combinar uma formação multifuncional, com o desenvolvimento de habilidades cognitivas e comportamentais que são indispensáveis para os avanços do mundo do trabalho. Voltando-se para o objetivo deste trabalho, onde se busca compreender as finalidades da educação profissional diante do contexto atual do mundo do trabalho, podese neste momento anunciar que a educação profissional precisa rever suas finalidades no sentido de incorporar conhecimentos nos currículos e na prática educativa, preparando os estudantes para um mundo de trabalho 
exigente e dinâmico que mantém sintonia orgânica com as demandas sociais, culturais e econômicas.

Para assegurar as análises e indicações propostas, este trabalho apresenta-se dividido em duas partes. Na primeira, recorrendo-se à literatura acadêmica disponível, são examinados aspectos relacionados com o mundo do trabalho na atualidade tendo a dimensão da globalização como conjuntura de análise. Na segunda parte são apresentadas finalidades da educação profissional, vista como possibilidade concreta de ingresso e manutenção das pessoas no mundo do trabalho. Essas duas partes são analisadas criticamente e a partir deste processo são enunciadas nas considerações finais desafios da educação profissional diante do contexto atual do mundo do trabalho.

Esta organização foi possível a partir da metodologia que foi adotada que se reveste de uma abordagem qualitativa, onde, por meio da pesquisa bibliográfica, foram apreendidas posições e tendências de autores que vem pesquisando sobre a temática nos últimos anos, tais como: Arroyo; Nosella (1999), Barato (2015), Casali (1997), Chiavenato (1999), Ciavatta; Frigotto; Ramos (2015), Enguita (2004), Frigotto (1989), Kuenzer (1997, 1999, 2005), Libâneo (2004), Manfredi (2015), Moura (2015), Offe (1995), Paiva (1997), Whitaker (1997), entre outros.

\section{GLOBALIZAÇÃO E O MUNDO DO TRABALHO}

No século XIX, Karl Marx chamava a atenção sobre a relação entre a indústria moderna e o desenvolvimento da maquinaria. Dizia este pensador que os modos de produção eram conservadores se comparados à base técnica da indústria que era revolucionária. Anunciava que se a classe trabalhadora adotasse o ensino tecnológico, teórico e prático, conquistaria o poder político.

No entanto, o que se constata atualmente é que diante das forças estabelecidas no mundo do trabalho, a educação vem se constituindo como um processo formativo de pessoas voltado para o mercado, sendo sujeitos 
empreendedores ou simplesmente consumidoras, nada diferente daquilo que no passado reproduzia relações sociais findadas na dominação de classe.

Neste sentido, Offe (1995, p. 73) pondera que a crise da sociedade do trabalho é percebida como uma mudança na qual o trabalho remunerado formal perde sua qualidade subjetiva. "[...] a denominação do mercado de trabalho como princípio alocativo vigente para organizar as atividades produtivas humanas e distribuir meios de subsistência pode obscurecer o fato de que o mercado é tudo, menos um mecanismo evidente por si próprio".

O trabalho é elemento constitutivo da dignidade humana que quando transformador atende a dimensão da ética. Quando pensado na dimensão técnica, logo vem à memória a capacitação profissional e o termo empregabilidade utilizado pelo mercado de trabalho.

Classificado como fonte de sustento, o trabalho é esforço despendido para a obtenção de outros valores, mas o que diferencia um trabalho dignificante de outro que desumaniza o homem, não é o objeto trabalhado ou matéria transformada, e sim, o conjunto das condições humanas ou desumanas sob as quais é executado.

$\mathrm{O}$ trabalho não pode ser reduzido a uma produção de subsistência. Ele apresenta um sentido mais abrangente, onde a educação ingressa nesse processo de capacitação permanente para que a pessoa exista com dignidade. Esta educação deverá transformar o ser humano integralmente, não só permitindo o desenvolvimento de suas habilidades, mas o desenvolvimento do sentido solidário e igualitário, sem egoísmos, individualismo e concorrente, promovendo em si uma reflexão crítica, participativa e emancipadora que desenvolva valores morais e éticos.

Possivelmente com o passar de algum tempo haverá a descentralização do trabalho, com a destruição dos ambientes organizados, tendo em vista que está decrescendo a participação do trabalho no tempo de vida das pessoas, emergindo um tempo livre que traz necessidades diferentes, novas orientações e experiências. Nesta perspectiva, Schaff (1990, p. 42) esclarece que o trabalho: 
pelo fruto do trabalho de alguém. [...] a eliminação do trabalho (no sentido tradicional da palavra) não significa o desaparecimento da atividade humana, que pode adquirir as formas das mais diversas ocupações.

Logo, é ilusão achar que trabalhadores com maior grau de empregabilidade terão condições de se ajustarem melhor às ofertas de emprego e aqueles competentes, estariam infinitamente mais protegidos do desemprego, improváveis afazeres ou outras tarefas informais. Para explicar tal termo e seu significado temos que:

Empregabilidade não é um desafio lançado a cada indivíduo trabalhador isoladamente para que dispute sua sobrevivência contra os outros competidores. [...] Não é apenas sua sobrevivência como trabalhadores no sentido estrito do que esta em jogo, mas sim, sobretudo, seu desenvolvimento continuado como seres humanos e o desenvolvimento da própria sociedade (CASALI, 1997, p. 113).

Com o desenvolvimento das relações produtivas capitalistas, o trabalho acabou se tornando um emprego, uma apropriação das organizações para produção de mercadorias. O trabalho para alguns virou uma atividade desvinculada de prazer, de satisfação, apenas uma obrigação necessária para o próprio sustento.

Nesta direção, a educação profissional deve ser vista como processo formativo para a classe trabalhadora, ou seja, como "formação para o trabalho" sem restringi-la em suas potencialidades, ampliando seu sentido para um paradigma humanista.

Note-se que tal concepção afina-se com o ideal de formação humana para o domínio do conhecimento técnico-científico e filosófico socialmente acumulado para sua aplicação diretamente produtiva, por meio do processo de trabalho. Como se percebe, ao ampliar-se a concepção de formação para o trabalho, ao contrário do senso comum, considera-se como uma prática corrente do mundo contemporâneo que engloba desde a escolarização básica até ações educativas voltadas para o desenvolvimento de aptidões para a vida produtiva.

Ficar atento ao mundo do trabalho é fundamental para quem está pretendendo investir em uma profissão ou carreira. No entanto, esta 
compreensão não pode se estender predominantemente as características que buscam num profissional. As novas regras estabelecidas no contexto atual do mundo do trabalho, as relações de competição e as exigências da globalização requerem profissionais com formação mais ampliada e cidadã.

Este contexto associa aqueles que oferecem mão de obra de trabalho àqueles que a procuram. A definição mais peculiar de mercado traz que nele se negocia, a fim de determinar os preços e as quantidades, preveem fenômenos de interação entre estes dois grupos, de empregados e empregadores, levando em conta a situação econômica e social de uma cidade, região, Estado ou país. Lacombe (2004, p. 210) conceitua mercado de trabalho como "[...] oferta e procura de mão de obra em determinada região. Inclui a determinação do valor da remuneração, dos benefícios e das condições de trabalho para cada tipo de profissional em determinada região em dado momento".

Ainda acrescenta Chiavenato que:

[...] as características do mercado de trabalho também influenciam o comportamento das pessoas e, em particular, dos candidatos a emprego. Quando o mercado de trabalho está em situação de oferta, existe excesso de vagas e oportunidades de emprego para os candidatos. Nestas circunstâncias, eles podem escolher e selecionar as organizações que oferecem as melhores oportunidades no mercado de trabalho, os empregados ficam encorajados a deixar seus atuais empregos para tentar melhores oportunidades em outras organizações (CHIAVENATO, 1999, p. 83).

Considerando as características do mercado de trabalho, as dinâmicas mundiais impostas pela economia, política e sociedade, demandam por uma educação profissional que contemple uma nova formação para um novo sujeito atuante no mundo do trabalho. Não se pode desconsiderar neste contexto que o estudante/trabalhador busca permanecer no mundo do trabalho. Há um empenho incessante na busca por um mundo igualitário e democrático, e o estudante/trabalhador que quer permanecer em uma área profissional deve estar sempre em busca de aprimoramento, atualizações, aperfeiçoamentos, podendo assim ser protagonista da sua própria história e estar satisfeito com suas escolhas. 
Deve estar atento a uma formação no seu sentido "lato" onde a preparação para o trabalho envolva ações educativas da sociedade com vista à adequação técnica, política e cultural da força de trabalho às necessidades da civilização e das relações de produção. No aspecto "estrito" aponta para a qualificação e atualização permanente da força de trabalho escolarizada para o domínio de aptidões técnico-produtivas adequadas ao trabalho nas empresas contemporâneas.

O mundo do trabalho têm levado sujeitos em busca por bancos escolares que deem essa preparação e garantam a empregabilidade, bem como cada vez mais as pessoas também estão mudando de carreira com vistas à identificação profissional e satisfação das necessidades do mercado de trabalho, ou seja, autogerenciando suas carreiras. Tem-se um mundo do trabalho onde o emprego tem como base o conhecimento, a aquisição de novas atitudes, habilidades e competências. Os trabalhadores deverão preparar-se continuamente, adquirindo competências e assumindo posturas. Estará inserida no perfil desse profissional a flexibilidade que deixará de ser uma característica para ser uma condição necessária para a sobrevivência.

O mundo do trabalho traz uma definição comum para caracterizar o mercado de trabalho formal e informal e tem como finalidade abranger toda e qualquer ocupação remunerada. O mérito está ligado à força, pois não existem pessoas profissionalmente satisfeitas sem que não tenham trabalhado ou tenham trabalhado pouco. Neste sentido, lanni acresce que:

O futuro cidadão do mundo não se define apenas pelo trabalho, marcado de força de trabalho, profissão e remuneração, emprego e desemprego. Define-se também por sua participação em partido político, sindicato, movimento social, como indivíduo e coletividade, envolve também a educação e a religião, a política e a cultura, a comunicação e a informação. Sob vários aspectos o indivíduo (IANNI, 2005. p. 31).

As mudanças no mundo do trabalho refletem esse pensamento e Kuenzer in Lombardi corrobora:

As mudanças ocorridas no mundo do trabalho a partir dos anos de 1990, com a globalização da economia, com a reestruturação produtiva e com as novas formas de relação entre Estado e sociedade civil a partir do neoliberalismo, mudam radicalmente as 
demandas de disciplinamento, e, em decorrência, as demandas que o capitalismo faz à escola (KUENZER, 2005, p.85).

Esclarece Enguita (2004, p. 67) sobre a diversidade crescente na comunidade global que "[...] embora o respeito para com o outro ou a igualdade de direitos de todos os cidadãos possam ser pregados pela família, de maneira alguma podem ter nela a materialidade prática e continuada que encontram na escola". Com essa pretensão, reforça Frigotto que a cidadania constitui-se como um direito fundamental na sociedade capitalista:

Do ponto de vista da gênese das relações capitalistas de produção, a condição histórica básica é, pois, que o trabalhador apareça no mercado de trocas para vender sua força de trabalho duplamente livre: livre no sentido que esteja destituído de propriedade, a não ser sua força de trabalho, e livre do domínio total de alguém sobre ele, de sorte que não só as relações de troca possam se efetivar, como se efetivem formalmente sob uma aparência legal (FRIGOTTO, 1989, p. 76).

Ainda nesta direção, Paulo Freire, um dos percussores da pedagogia crítica, era otimista com relação à mídia e as novas tecnologias e trazia uma dupla visão sobre esses instrumentos: como potenciais de "[...] empoderamento dos cidadãos e de dominação nas mãos das elites governantes". Burbules; Torres (2004, p. 206) transcreve o que Paulo Freire escreveu: "[...] a formação técnica e científica não precisa ser inimiga da educação humanista, pois a ciência e a tecnologia na sociedade revolucionária estão a serviço da libertação permanente, da humanização".

Para Burbules; Torres (2004, p. 38) o efeito é voltar à educação para "[...] capacidades baseadas em competências, às custas das formas mais fundamentais de competências críticas exigidas para um aprendizado autônomo e uma cidadania crítica". Num outro estudo Manfredi (1999, p. 12) define a competência dos profissionais "[...] como o domínio de técnicas e conteúdos atinentes ao seu campo profissional de atuação, expressos por meio da apropriação dos conhecimentos historicamente acumulados no campo das ciências e da tecnologia".

Diante de tantas incertezas, segue neste cenário uma crise do modo de produção capitalista, causa e consequência da "globalização" que gera um colapso mundial não ainda totalmente visível. Neste modo de produção, a 
estruturação do trabalho marcou não apenas o trabalhador, na sua forma de sobreviver, mas o homem ser social, na sua forma de ocupação para realizar suas potencialidades. Esclarece Whitaker (1997, p. 8) que a globalização quer uma pessoa "[...] que tenha conhecimento da cidade, que possua formação profissional multidisciplinar, que esteja identificada com a tradição de justiça social e de defesa dos direitos humanos, e que entenda a diversidade cultural, étnica e religiosa".

A globalização cultural acende constituída de histórias locais que incrustam mudanças culturais, históricas, econômicas e sociais que se moldaram devido a essa globalização. É possível perceber que esses efeitos homogêneos são articulados nos campos sociais, não desencadeando resultados tão satisfatórios a nível mundial, pois se existe uma razão que sintetize a razão ocidental e a alta modernidade, é a alfabetização crítica.

Percebendo tudo isso num mundo globalizado, com economia de informação hightech, é possível compreender essas modificações e também continuar a promover habilidades tradicionais relativas ao conhecimento e a crítica a fim de atingir objetivos progressistas nas organizações. Por ser uma ordem atual naquilo que está sendo vivenciado, "novas alfabetizações" surgirão relacionadas com a mídia e os avanços tecnológicos na informática.

Os processos de modernização organizacional e técnica desencadeados em determinadas organizações produtivas têm acompanhado a ação da globalização da economia capitalista e os impactos destas transformações sobre o mundo do trabalho e as qualificações estão se redefinindo.

Essa busca incessante por um lugar ao sol instiga uma briga acirrada entre aqueles que têm emprego e os que não têm trabalho formal. Com um emprego é possível gozar dos direitos legais e fazer carreira, mas mesmo aqueles que estão empregados formalmente sofrem pressão para aceitar a flexibilização com a redução de seus salários. Essas mudanças geram trabalhadores polivalentes e multifuncionais, mas por outro lado pode tornálos empregados temporários ou desempregados.

Há quem diga que os avanços tecnológicos e científicos juntamente com a globalização estão modificando a sociedade do trabalho e do 
conhecimento, propiciando assim a valorização crescente da educação e qualificação profissional, acarretando transformações nas relações de trabalho. Exigências crescentes no setor produtivo, redução na oferta de vagas e empregos formais, ou seja, precarização do trabalho (empregos parciais ou temporários, informais, subcontratados ou terceirizados e flexíveis) estão provocando aumento no desemprego e a exclusão social.

Para Burbules; Torres (2004, p. 14-15) “[...] a reestruturação econômica levou a uma crescente proletarização e desespecialização do emprego". A economia passou por uma unificação do capital em escala mundial, empresas multinacionais podem ter uma base nacional clara, mas seu interesse está acima de tudo na lucratividade global.

Diante dessas considerações, constata-se que os desafios são muitos, podendo se destacar a educação profissional diante do contexto atual do mundo do trabalho, onde a prática sempre constrói um novo conhecimento, ou seja, o fazer incorporado ao saber. Arroyo (1999, p. 101) destaca que "[...] o desafio, enfim, de unir a educação ao trabalho de tal modo que o processo educativo, enquanto gerador de sujeitos esteja situado no coração mesmo de um sistema produtivo humanizado". Para isso torna-se necessário multiplicar instituições de educação profissional e sistemas educativos para desenvolver esse processo - educação e trabalho - orientado para uma visão global/mundial, associada as suas competências, talentos, capacidades e trocas multiculturais que possibilitarão desenvolvimento moral.

\section{EDUCAÇÃO PROFISSIONAL E SUAS FINALIDADES}

Atento as novas demandas e aos novos paradigmas do mundo do trabalho e da educação o sistema educacional brasileiro adaptou-se a nova realidade, a partir da Lei de Diretrizes e Bases da Educação Nacional - LDB Lei no 9.394/1996, que instituiu a educação regular em educação básica e superior. Para a educação profissional a LDB e sua regulamentação (Decreto Federal no 5.154/2004 e Lei no 11.741/2008, art. 39), estabeleceram três modalidades: formação inicial e continuada ou qualificação profissional, 
educação profissional técnica de nível médio e educação profissional tecnológica de graduação e pós-graduação.

Com essas atualizações, as diretrizes curriculares buscam maior articulação entre os saberes da educação com os saberes do mundo do trabalho, ganhando destaque o desenvolvimento de competências por meio da manutenção do sujeito em atividades geradoras de renda que assegurem sua mobilidade ocupacional e social.

A LDB n 9.394/1996 está organizada como tentativa de eliminar a dualidade e como forma de unificação da teoria com a prática:

\begin{abstract}
A lei $n^{0} 5.692 / 71$ surge no sentido de eliminar tal dualidade ao tornar compulsória a profissionalização ao nível de $2^{\circ}$ grau [...] nos sistemas estaduais de ensino a profissionalização compulsória foi amplamente problemática e não foi implantada completamente. Em primeiro lugar, porque a concepção curricular que emanava da Lei empobrecia a formação geral do estudante em favor de uma profissionalização instrumental para o "mercado de trabalho" sob a alegação da importância da relação entre teoria e prática para a formação integral do cidadão (MOURA, 2007, p. 12).
\end{abstract}

Na década de trinta que pode ser tomada como um marco referencial na história da política da educação nacional iniciava-se o processo de industrialização do país. As linhas de ação das instituições como o SENAI e SENAC basearam-se durante muito tempo, no treinamento das técnicas para o preenchimento de postos de trabalho bem definidos, com ênfase na preparação para "o fazer".

Na história da educação, os tecnocratas tornaram-se visíveis a partir do Estado Novo em meados dos anos 1937 a 1945. O presidente Getúlio Vargas, chamado de "Pai dos Pobres", incentivou o desenvolvimento da mão de obra nacional como forma de proteger atividades econômicas já existentes e para aquelas que ainda surgiriam. Diante disso, o governo criou um ensino público paralelo ao sistema profissionalizante da época, instituído pelo SENAI, SENAC (sistema S) que demonstravam um crescimento vigoroso, pois os estudantes que ali passavam aprendiam um ofício e ainda recebiam uma bolsa-remuneração para estudar e colocar os estudos em prática dentro das empresas. 
Além de apresentar uma nova concepção de qualificação para o trabalhador, inseriram em seu discurso inquietações referente ao cidadão:

\begin{abstract}
Estas instituições como também o SENAI e o SENAC, atendendo a várias pressões do processo democrático com suas novas exigências de participação, do processo produtivo e de sua nova concepção de qualificação dos trabalhadores e dos estudantes, passaram a incorporar conteúdos nesta linha e a incluir no seu discurso a preocupação não só com o trabalhador, mas com o cidadão (KUENZER, 2007, p. 84).
\end{abstract}

$\mathrm{Na}$ época, as organizações compreendiam que seu principal capital eram os recursos humanos, nada diferente dos nossos tempos contemporâneos. Naquele tempo e hoje ainda os trabalhadores entendem que a qualificação é necessária para a inserção no mundo do trabalho.

Os cursos oferecidos por instituições profissionalizantes ainda visam agregar formação profissional e preparação para o trabalho, ambas firmadas em conhecimentos, princípios e valores que potencializam a busca de caminhos dignos em que foram estabelecidas. Abordam trabalho, ciência e cultura nas perspectivas de emancipação, pois adotam orientação pedagógica e pensamento analítico, procurando formar profissionais abrangentes, flexíveis e qualitativamente de nível elevado para a sociedade na qual estão inseridos. Há a tendência de organização curricular com foco no desenvolvimento das competências profissionais.

Disposições legais atribuem às agências de educação profissional, autonomia para organizar currículos de cursos técnicos, desde que tomem como referência as Diretrizes Curriculares Nacionais, considerando seus respectivos projetos pedagógicos e as peculiaridades regionais.

Essas instituições do Sistema $S$ proporcionam oportunidades para aprender uma profissão, com aulas práticas e laboratórios equipados, além das opções de encaminhamento ao mundo do trabalho. Os instrutores são profissionais com experiência no mundo do trabalho e metodologias de aprendizagem baseadas no desenvolvimento de competências e na prática profissional.

O ingresso do jovem no mundo do trabalho deve ser revisto em alguns critérios de avaliação, cabendo aos profissionais envolvidos neste processo 
sua própria formação para acompanhar as mudanças impostas no mundo do trabalho. Com esse pensamento Durkheim (1978, p. 81) esclarece que "[...] o homem que a educação deve realizar, em cada um de nós, não é o homem que a natureza fez, mas o homem que a sociedade quer que ele seja; e ela o quer conforme o reclame a sua economia interna, o seu equilíbrio". Nesse mesmo sentido Frigotto; Ciavatta; Ramos confirmam que o ensino médio então não deveria formar técnicos especializados, mas sim politécnicos:

\begin{abstract}
O papel do ensino médio estaria orientado à recuperação da relação entre conhecimento e a prática do trabalho, o que denotaria explicitar como a ciência se converte em potência material no processo produtivo. Dessa forma, seu horizonte deveria ser o de propiciar aos alunos o domínio fundamental das técnicas diversificadas utilizadas na produção, e não o mero adestramento em técnicas produtivas (FRIGOTTO; CIAVATTA; RAMOS, 2005, p. $35)$.
\end{abstract}

A escola desempenha um importante papel no sentido de formar e aprimorar as pessoas, mas ela não consegue sozinha garantir tudo aquilo a que se propõe, ou seja, desenvolver plenamente as potencialidades individuais dos estudantes, capacitá-los para o trabalho, formá-los cidadãos conscientes e aptos para o exercício pleno de sua cidadania.

Neste mesmo contexto Libâneo (2004, p. 230) explica que: [...] é difícil pensar na possibilidade de educar fora de uma situação concreta e de uma realidade definida. Por essa razão, a ênfase na prática como atividade formativa é um dos aspectos centrais a ser considerado, com consequências decisivas para a formação profissional.

Diante desses excertos é possível perceber que a educação é um processo multifacetado que transcende o espaço escola. Ela envolve atitudes, consciência, habilidades e crítica objetivando a formação de um sujeito. Entre tantas teorias que justificam os novos padrões de produção, podemos observar que hoje a educação faz ponte para o mundo do trabalho, pois a escola torna-se um espaço de construção e reprodução de conhecimentos científicos, relações e ideologias. Nesta perspectiva:

Não se trata apenas de qualificar para o trabalho em si, mas de formar para a vida na qual também se insere o trabalho nem sempre como foco fundamental da existência, com uma flexibilidade 
e um alcance suficientes para que se possa enfrentar o emprego, o desemprego e o autoemprego - de modo a permitir rápidas reconversões e reprofissionalizações ao longo da vida (PAIVA, 1997, p. 131).

Para muitos jovens a escola é o lugar onde passam grande parte de suas vidas, mais por uma questão de exigência e obrigatoriedade da sociedade atual do que por vontade própria. É necessário que esse cenário educacional seja reformulado em sua função e responsabilidade social de promover oportunidades para a aprendizagem. Para Frigotto a escola como formação social passa por dois aspectos:

\footnotetext{
1) compreensão teórica que une ensino e trabalho produtivo, escola politécnica e trabalho como princípio educativo.

2) concretização do trabalho como princípio educativo e como elemento da unidade entre a dimensão técnica e política da prática educativa escolar e as práticas fundamentais - socialização dos resultados do trabalho coletivo (FRIGOTTO, 1989, p. 187).
}

Diante desse fundamento, cabe à escola promover uma formação profissional com qualidade para na idade adulta, os jovens ingressarem mais firmemente no mundo do trabalho. $O$ trabalho e a educação profissional terão que estar atento de um lado ao mercado que demanda trabalhadores e de outro os jovens que clamam por mais oportunidades e liberdade. A qualificação tornou-se um pré-requisito e também é usada como fator eliminatório para a contratação de um novo trabalhador. Esse estudante/trabalhador deve buscar capacitação por meio de cursos contínuos, adquirindo assim, conhecimentos cognitivos e habilidades que permitam estar apto a pensar, criticar e a solucionar problemas de forma inteligente, rápida e participativa.

Muitas organizações buscam profissionais que apresentam um perfil mais preparado, com conhecimento e comprometimento, mas infelizmente as disparidades existentes no mercado fazem com que as mesmas entendam que alguns jovens não oferecem atitude e empenho, são frágeis, demonstram ineficiência, o que faz com que a empresa persista na busca constante desse perfil, num mercado seletivo e competitivo. As adaptações para os novos tempos estão substituindo a tecnologia ultrapassada por outras novas, trocando o trabalho manual/artesanal pelo robotizado, trazendo como 
consequências o afunilamento na contratação de pessoas e o barateamento nos salários e remunerações. Em concordância com essa situação comenta Franco (1988, p. 82-83) que as aspirações de alguns estudantess são condicionadas pelo meio em que vivem, assim, "[...] a escola, sem dúvida, deve levar em conta o mercado de trabalho, deve levar em conta suas características fundamentais numa sociedade determinada", corroborando nesse sentido ainda acrescenta:

\begin{abstract}
A formação profissional é vista como uma resposta estratégica, mas polêmica, aos problemas postos pela globalização econômica, pela reestruturação produtiva, pela busca da qualidade $e$ da competitividade, pelas transformações do mundo do trabalho e pelo desemprego estrutural. [...] Do ponto de vista dos empresários, a formação profissional tem como endereço claro, aumentar a produtividade do trabalho, a qualidade e a competitividade dos produtos, gerar riqueza (FRANCO, 2004, p. 101).
\end{abstract}

Discordando dessa função escolar, Enguita (2004, p. 50) afirma que a escola "[...] nasceu como uma instituição decididamente de assimilação, uniformizadora, uma máquina de fabricar súditos ou cidadãos". Neste mundo globalizado, nada mais é único e sim ocorrem mesclas de culturas, identidades, valores. Há a compreensão de outras linguagens, crenças e novas diretrizes de comportamento. O mundo do trabalho passa a exigir novos trabalhadores com formação polivalente, articuladores de conhecimento científico e do saber fazer. Pessoas/profissionais que exerçam funções de produtores e de cidadãos, capazes de atuar intelectualmente dominando tarefas específicas de organização e gestão, que compreendam as relações são amplas na constituição da sociedade. Nesse sentido, Casali (1997, p. 182) entende que seria necessário modernizar as relações sociais por meio de "[...] uma articulação orgânica entre todos os atores individuais e institucionais, implicados na questão: trabalhadores, sindicatos, direção de empresa, escola, órgãos governamentais, eventuais organizações não governamentais".

Dentro desse conjunto direcionado ao mundo do trabalho, há as características que um profissional deve possuir ou desenvolva para que ele realize suas funções a nível laboral que expandiu, passando a exigir 
capacidade de educar-se permanentemente e autonomia para criar métodos para enfrentar problemas complexos e situações não previstas.

Para isso é necessário um processo de qualificação direcionado para o mundo do trabalho que:

\begin{abstract}
Envolve um processo de formação profissional adquirido por meio de um percurso escolar e de uma experiência (ou carreira profissional) capaz de preparar os trabalhadores para o ingresso e a manutenção no mercado formal de trabalho. Para outros o processo de qualificação/desqualificação é um resultado da relação social entre capital e trabalho e da correlação de forças entre ambos (MANFREDI,1999, p. 13).
\end{abstract}

A ideia de inserção no mundo do trabalho pressupõe a passagem por um processo de formação escolar que é fundamental quando se trata de definir os princípios norteadores da práxis de uma instituição de educação profissional. Concordando com esse papel da escola em formar sujeitos polivalentes, Franco (1988, p. 86) considera que "[...] com isso, estaria dando a sua contribuição para que o futuro trabalhador tivesse acesso às novas contribuições da ciência e da técnica que, por sua vez, deverão ser revolucionadas pelo coletivo dos trabalhadores".

O desafio é educar o estudante/trabalhador no sentido de atuar de modo participativo e ativo dentro e fora do mundo do trabalho, como profissional, e também, na condição de cidadão consciente de seus direitos e responsabilidades e dos valores humanos que devem reger a vida em sociedade.

Com esse pensamento elucida Manfredi que:

O processo de reorganização da economia mundial e as transformações técnico-organizacionais não só têm afetado as condições, os meios e as relações de trabalho, como também estão associados à construção de novas formas de representação ou ressignificação das noções de trabalho, qualificação, competência e formação profissional (MANFREDI, 1999, p. 9).

O desenvolvimento se dá pela comunicação bidirecional, que propicia a interatividade e a colaboração dentre os demais participantes. Dentro desse contexto de socialização é possível constatar que: 
Se o conhecimento é, portanto, elaborado socialmente a partir do trabalho dos homens que estabelecem relações entre si e na produção da existência, processo pelo qual se constitui sua consciência, é inegável o fato de que o operário produz conhecimento. [...] ele vai experimentando, analisando, refletindo, indagando, discutindo, descobrindo; e desta forma ele vai construindo um conjunto de explicações para sua própria ação, ao mesmo tempo em que vai desenvolvendo um conjunto de formas próprias de "fazer" (KUENZER, 1997, p. 183).

Essa questão da diversidade tem sido pensada em vários espaços sociais, principalmente em locais que deparam com essa desigualdade na sua construção histórica, cultural e social. Nas tentativas de importar e reproduzir estratégias educacionais, os legisladores enfrentam processos de inflexões e adaptações na tentativa de implementar um currículo com abordagens padronizadas na instrução onde a ideia era expandir a educação universal, além do nível de escolas secundaristas, visando programas que lidem com a diversidade cultural além daquele conteúdo comunitário, local e étnico já existente. Essa desigualdade social e fragmentação cultural faz com que a educação também se torna um bem de consumo individualizado, que é oferecido em um mundo global e acessado por poucos por meio de conexões via satélite.

A escolarização no Brasil é uma das mais baixas dependendo das regiões. Um dos desafios reside na luta por um mundo de justiça onde haja a ampliação dos saberes para essa camada da população mais humilde e carente de educação, para que possam melhorar não somente esse aspecto, mas também no labor, nas interelações com os demais indivíduos, mas que esses "conhecimentos" possam melhorar sua condição de vida, sua inclusão na sociedade e status.

Antigamente acreditava-se nesse reconhecimento formal, pois a economia e a educação trabalhavam essa qualificação, ou seja, o mundo do trabalho determinava certa demanda de profissionais e isso definia o número de diplomas. Os currículos desenvolvidos asseguravam valores éticos, conhecimento, cultura, formação, diversidade e a avaliação do desempenho do indivíduo. Mesmo assim, ainda existem jovens que preferem adiar a entrada no mundo do trabalho e acabam se dedicando exclusivamente aos estudos. São jovens sustentados financeiramente pelos pais que buscam 
aumentar sua bagagem intelectual e obter melhores cargos e vantagem a partir disso.

O currículo é uma construção e seleção de conhecimentos e práticas, segundo vem sendo produzidas em:

\begin{abstract}
Contextos concretos e em dinâmicas sociais, políticas e culturais, intelectuais e pedagógicas. Conhecimentos e práticas expostos às novas dinâmicas e reinterpretados em cada contexto histórico. As indagações revelam que há entendimento de que os currículos são orientados pela dinâmica da sociedade (MOREIRA; CANDAU, 2007, p. 9).
\end{abstract}

Para Kuenzer (1999, p. 22) o currículo mantém relação direta com "[...] o valor do certificado, pois este abre as portas para o exercício das funções intelectuais no mercado de trabalho e confere as habilidades, comportamentos e conhecimentos minimamente necessários para a aquisição de competência por meio do exercício profissional".

Oposto a isso, cresce o número de jovens que buscam a educação profissional para obter formação em menor período de tempo. É a alternativa para quem não pode ingressar na educação superior ou que preferem concluir um curso técnico antes de começar a mesma. Desta forma podem obter uma visão mais clara da área em que pretende atuar. Esse ensino técnico agrega ao estudante capacidades semelhantes às que são desenvolvidas no mundo do trabalho, além de diferenciá-lo em conhecimento técnico dos demais jovens.

Nesta direção, Frigotto salienta que:

O que se impõe como necessário, é uma escola organizada de tal
sorte que possibilite ao trabalhador o acesso ao "saber objetivo"
elaborado, sistematizado e historicamente acumulado. [...] Trata-se
de uma escola cujo conteúdo se elabora tendo como ponto de
partida a própria experiência e realidade da classe trabalhadora
(FRIGOTTO, 1989, p. 207).

Essa possibilidade de qualificação, do trabalho e do trabalhador, embutida no conjunto de transformações econômicas e tecnológicas, favorece a história das instituições que oferecem profissionalização que se enquadra na lógica da qualificação entendida como preparação para o mundo 
do trabalho, pois gera mão de obra especializada ou semiespecializada. Neste âmbito Barato comenta sobre os:

\begin{abstract}
Cursos que os alunos utilizam como mecanismo de passagem, tanto para incorporação provisória ao mercado de trabalho quanto como mecanismo conveniente para acesso ao ensino superior, enfrentam dificuldades para desenvolver valores vinculados ao trabalho que é objeto de educação sistemática (BARATO, 2015, p. 43).
\end{abstract}

Diante desta declaração decorre uma indagação, ou seja, como incentivar esses jovens a escolherem uma profissão. E ainda reforça que outros estudantes com melhores possibilidades financeiras ainda buscam:

\begin{abstract}
O curso para aumentar suas chances de ingresso imediato no mercado, mas sem planos de continuar na função ou fazer carreira no setor. Qualquer outro curso técnico, desde que acenasse com possibilidades de emprego, poderia cumprir o papel esperado por esses alunos. [...] Uma oportunidade educacional como forma de acomodação provisória de alunos que aguardam ingresso no ensino superior (BARATO, 2015, p. 37).
\end{abstract}

Independente das possibilidades, ultimamente se verifica que estudar possibilita a emancipação do sujeito para o trabalho e pelo trabalho como ponto de partida para assumir condições singulares na sociedade. Uma organização busca sempre o melhor perfil para sua necessidade, concentrando sua escolha no profissional mais motivado e mais preparado. Destaca Frigotto (1989, p. 220) que a forma adequada de ascender na vida é mediante a hierarquia dos postos de trabalho nas diferentes escalas profissionais, onde o fator educação ou treinamento é determinante para que "[...] a eliminação da desigualdade social, da desigualdade de classes se atingiria mediante, especialmente, o investimento no capital humano. Erige-se por essa via, o conceito ideológico de trabalho (reduzido a emprego ou ocupação) e de trabalho potencializado por treinamento e educação".

\title{
4 CONSIDERAÇÕES FINAIS
}

Considerando a necessidade da realização permanente de pesquisas sobre esta temática, este trabalho, ao buscar compreender as finalidades da 
educação profissional diante do contexto atual do mundo do trabalho, se constitui em instrumento de socialização dos conhecimentos produzidos sobre a temática. O caminho percorrido nesta produção mostrou que as transformações ocorridas das últimas décadas no mundo do trabalho, no que diz respeito às várias questões atualmente assentadas no cenário mundial, como a globalização, a produção flexível e as novas exigências do mercado, afetam diretamente as pessoas. As novas tendências organizacionais e as mudanças tecnológicas estão tornando o mundo do trabalho mais exigente e seletivo.

Chegando-se a uma tentativa de finalização, é importante ressaltar que o processo de globalização econômica e de reestruturação produtiva provocam mutações nos processos de qualificação dos trabalhadores e, é premente que estas transformações exigem profundas alterações nas ações de formação profissional. As demandas do mundo do trabalho justificam a adoção de constantes reformas no sistema educacional. Neste sentido, percebe-se os motivos pelos quais se busca a formação profissional como um componente essencial devido à importância de uma força de trabalho qualificada na definição dos diferentes caminhos que pode seguir uma política social.

Assim, os estudantes/trabalhadores, em plena era da globalização, assumem uma nova roupagem nesse contexto de reestruturação produtiva, considerada mais fragmentada, mais heterogênea e ainda mais diversificada. Pode-se constatar, neste processo, uma perda significativa de direitos e de sentidos, em sintonia com o caráter destrutivo do capital vigente, tornando o trabalho ainda mais precarizado, por meio das formas de subemprego, desemprego, intensificando os níveis de exploração para aqueles que trabalham.

As referências analisadas dos autores envolvidos neste trabalho apontam que a educação profissional tem 0 desafio de garantir aos estudantes 0 desenvolvimento de habilidades relacionadas com 0 desempenho polivalente e atualização permanente. Além disso, deve se fundamentar em perfis profissionais que sejam significativos para a sociedade 
em um desenho curricular que seja flexível orientado para a formação profissional autônoma e cidadã.

Deve considerar que com a inserção das novas tecnologias o mundo do trabalho passou a exigir uma formação cada vez mais qualificada dos estudantes/trabalhadores, sendo que os com baixa escolarização vão sendo descartados do mercado em detrimento aos mais capacitados e com maior gama de competências. Neste contexto, uma nova configuração do mundo do trabalho vai se constituindo com uma parte de trabalhadores assalariados, formada por operários e empregados altamente qualificados, e por outro lado, outra parte precária, ampliada, objeto de exploração capitalista.

Defronte desse contexto de reestruturação produtiva, cabe à educação profissional que mantém relação estreita com as forças produtivas da sociedade, formar os trabalhadores no sentido de oferecer condições para que os mesmos possam adquirir habilidades cognitivas que os permitam pensar, a serem críticos, a resolverem problemas, de forma inteligente, ativa e participativa nessa nova configuração do mundo do trabalho.

Deve favorecer o desenvolvimento de competências laborais e o aumento da empregabilidade, estabelecendo uma relação entre a ação educativa, a autonomia e o acesso ao mundo do trabalho. Neste cenário, pode-se dizer que cada pessoa é responsável por sua condição na sociedade e leva em consideração o reforço da lógica meritocrática - do fracasso ou sucesso (arsenal de competências acumulado pelo sujeito e disponibilizado para o trabalho). Este aspecto mantém vinculação com o sistema neoliberal, onde as relações de sucesso neste mundo/contexto competitivo se relacionam diretamente com aquilo que colocou em prática para alcançar sucesso em suas metas e objetivos.

Os estudantes/trabalhadores só estarão preparados para o contexto atual do mundo do trabalho se estiverem explorando suas potencialidades. Assim, a possibilidade de formação o tornará um cidadão mais profissional, responsável, com habilidades cognitivas, autoconfiante, flexível, a fim de alcançar reconhecimento, trabalhar em equipe e mediar conflitos. Em resumo, aprender na escola e fora dela deve fazer parte do mundo do trabalho contemporâneo. 
Essas assertivas acompanhadas dos apontamentos mostrados anteriormente sugerem outras buscas teóricas e novas análises de novos dados sobre as finalidades da educação profissional diante do contexto atual do mundo do trabalho. Essas considerações aqui situadas são correntes e necessitam ser aprofundadas e melhor validadas em outros trabalhos de pesquisa. Trata-se de um tema fecundo para novas investigações, não só para recriar a educação profissional como também para possibilitar a formação de profissionais autônomos, participativos e críticos, capacitados a refletir e produzir novos conhecimentos, tendo como ponto de partida e de chegada da apreensão a realidade. Cabe ainda considerar que todo esforço dispensado na transformação da educação profissional deve contribuir para ampliar as oportunidades educacionais e o tempo de escolarização das pessoas e de transformar as instituições de ensino.

\section{REFERÊNCIAS}

ARROYO, M.; NOSELLA, P. Trabalho e conhecimento: dilemas na educação do trabalhador. 6. ed. São Paulo: Cortez, 1999.

BARATO, J. N. Fazer bem feito - valores em educação profissional e tecnológica. Brasília: UNESCO, 2015.

BURBULES, N.; TORRES, C. A. (Orgs.) Globalização e Educação: perspectivas críticas. Trad. Ronaldo Cataldo Costa. Porto Alegre: Artmed Editora, 2004.

CASALI, A. (Coord.) Empregabilidade e educação: novos caminhos no mundo do trabalho. São Paulo: EDUC - Editora da Pontifícia Universidade Católica de São Paulo, 1997.

CHIAVENATO, I.. Gestão de Pessoas: o novo papel dos recursos humanos nas organizações. Rio de Janeiro: Campus, 1999.

CIAVATTA, M.; FRIGOTTO, G.; RAMOS, M.. A gênese do Decreto no 5.154/2004: um debate no contexto controverso da democracia restrita. In: Trabalho necessário. Revista Eletrônica do neddate, 2005. p. 35. Disponível em <http://www.uff.br/trabalhonecessario/MMGTN3.htm>. Acesso em: 02 ago. 2015.

DURKHEIM, É. Educação e sociologia. 11. ed. São Paulo: Melhoramentos, 1978.

ENGUITA, M. F. Educar em tempos incertos. Tradução Fátima Murad. Porto Alegre: Artemed, 2004.

FRANCO, L. A. C. A escola do trabalho e o trabalho da escola. 2. ed. São Paulo: Cortez, 1988. 
FRIGOTTO, G. A produtividade da escola improdutiva: um (re)exame das relações entre educação e estrutura econômico-social e capitalista. 3. ed. São Paulo: Cortez: Autores Associados, 1989.

FRIGOTTO, G.; FRANCO, M. A. C. (Coord.). Ensino médio: ciência, cultura e trabalho. Brasília: Ministério da Educação e Cultura, 2004.

IANNI, O. Pensamento Social no Brasil. Bauru: Ed. Universidade do Sagrado Coração, 2005.

KUENZER, A. Z. Ensino médio e profissional: as políticas do Estado neoliberal. São Paulo: Cortez, 1997.

KUENZER, A. Z. Planejamento e educação no Brasil. 4. ed. São Paulo: Cortez, 1999.

Ensino Médio e Profissional: as políticas do Estado neoliberal. 4. ed. São Paulo: Cortez, 2007.

Exclusão Includente e Inclusão Excludente: a nova forma de dualidade estrutural que objetiva as novas relações entre trabalho e educação. In: LOMBARDI J. C.; SAVIANI D.; SANFELICE, J.L. (Orgs). Capitalismo, trabalho e educação. Campinas, SP: Autores associados, HISTEDBR, 2005.

LACOMBE, F. J. M. Dicionário de administração. São Paulo: Saraiva, 2004.

LIBÂNEO, J. C. Organização e gestão da escola: teoria e prática. 5. ed. Revista e ampliada. Goiânia: Editora Alternativa, 2004.

MANFREDI, S. M. Trabalho, qualificação e competência profissional: das dimensões conceituais e políticas. Educação \& Sociedade. Campinas, SP, v. 19 n. 64, p. 9-13, 1999. Disponível em: <http://dx.doi.org/10.1590/S0101-73301998000300002>. Acesso em: 24 jul. 2015.

MOURA, D. H. Educação Básica e Educação Profissional e Tecnológica: dualidade histórica e perspectivas de integração, RN, v. 2, n. 23, p. 12, 2007. Disponível em: http://www2.ifrn.edu.br/ojs/index.php/HOLOS/article. Acesso em 26 jul. 2015.

MOREIRA, A. F. B.; CANDAU, V. M. (Orgs.). Indagações sobre currículo: currículo, conhecimento e cultura. Brasília: Ministério da Educação, Secretaria de Educação Básica, 2007.

OFFE, C. Capitalismo desorganizado: transformações contemporâneas do trabalho e da política. 2. ed. São Paulo: Brasiliense, 1995.

PAIVA, V. Desmistificação das profissões: quando as competências moldam as formas de inserção no mundo do trabalho. Revista Contemporaneidade e Educação, Rio de Janeiro: IEC, n.1, 1997.

SCHAFF, A. Sociedade Informática. São Paulo: Brasiliense, 1990. 
WHITAKER, D. Escolha da carreira e globalização. 11. ed. rev. e ampl. São Paulo: Moderna, 1997. 